Article

\title{
Selective Adsorption-Based Separation of Flue Gas and Natural Gas in Zirconium Metal-Organic Frameworks Nanocrystals
}

\author{
Pengli Li ${ }^{1}$, Yongli Shen ${ }^{1}$, Dandan Wang ${ }^{1}$, Yanli Chen ${ }^{2, *}$ and Yunfeng Zhao ${ }^{1, *}$ \\ 1 Tianjin Key Laboratory of Advanced Functional Porous Materials, Institute for New Energy Materials \& \\ Low-Carbon Technologies, Tianjin University of Technology, Tianjin 300384, China; lp1929@163.com (P.L.); \\ panger_shen@126.com (Y.S.); 15510906816@163.com (D.W.) \\ 2 School of Materials Science and Engineering, Tianjin University of Technology, Tianjin 300384, China \\ * Correspondence: yanlichen@live.com (Y.C.); yfzhao@tjut.edu.cn (Y.Z.); Tel.: +86-22-6021-6415 (Y.Z.)
}

Academic Editor: Takei Takahiro

Received: 6 May 2019; Accepted: 8 May 2019; Published: 11 May 2019

\begin{abstract}
Carbon capture from flue gas and natural gas offers a green path to construct a net-zero emissions economic system. Selective adsorption-based gas separation by employing metal-organic frameworks (MOFs) is regarded as a promising technology due to the advantages of simple processing, easy regeneration and high efficiency. We synthesized two Zirconium MOFs (UiO-66 and UiO-66- $\mathrm{NH}_{2}$ ) nanocrystals for selective capture and further removal of $\mathrm{CO}_{2}$ from flue gas and natural gas. In particular, $\mathrm{UiO}-66-\mathrm{NH}_{2}$ nanocrystals have a smaller grain size, a large amount of defects, and pending $-\mathrm{NH}_{2}$ groups inside their pores which display effective $\mathrm{CO}_{2}$ selective adsorption abilities over $\mathrm{CH}_{4}$ and $\mathrm{N}_{2}$ with the theoretical separation factors of 20 and 7. This breakthrough experiment further verified the selective adsorption-based separation process of natural gas and flue gas. In one further step, we used the Monte Carlo simulation to investigate the optimized adsorption sites and energy of $\mathrm{CO}_{2}, \mathrm{~N}_{2}$ and $\mathrm{CH}_{4}$ molecules in the gas mixture. The significantly large adsorption energy of $\mathrm{CO}_{2}$ $(0.32 \mathrm{eV})$ over $\mathrm{N}_{2}(0.19 \mathrm{eV})$ and $\mathrm{N}_{2}(0.2 \mathrm{eV})$ may help us to reveal the selective adsorption mechanism.
\end{abstract}

Keywords: UiO-66; carbon capture; gas separation; flue gas; methane

\section{Introduction}

Carbon dioxide $\left(\mathrm{CO}_{2}\right)$ is regarded as the primary anthropogenic culprit for global warming and climate change, which is produced by fossil fuel [1]. The atmospheric $\mathrm{CO}_{2}$ concentration has increased approximately 300-400 ppm over the last 50 years (1960-2016) [2], and is speculated to reach more than $500 \mathrm{ppm}$ by 2050 [3]. The main emission source of $\mathrm{CO}_{2}$ is the combustion of fossil fuels such as coal, oil, and natural gas. Carbon capture is broadly identified as possessing the great potential to play a critical role in meeting climate change targets [4]. Effective carbon capture is regarded as one key node of the net-zero emission energy system [1]. The major demand for carbon capture comes from the treatment of $\mathrm{CO}_{2}$ mixture gas including power-plant flue gas, raw natural gas, coal-bed gas, and biogas in which $\mathrm{CO}_{2}$ is in wide concentration range and is mixed with different gases. For example, about $5 \%-15 \%$ of $\mathrm{CO}_{2}$ is majorly mixed with $\mathrm{N}_{2}$ in power-plant flue gas, and a wide range of $\mathrm{CO}_{2}$ is regarded as an impurity of methane $\left(\mathrm{CH}_{4}\right)$ for the raw natural gas $\left(\mathrm{CH}_{4}:>90 \%, \mathrm{CO}_{2}: 0.5-1 \%\right)$ and coal-bed $\left(\mathrm{CH}_{4}:>50 \%, \mathrm{~N}_{2}: \sim 40 \%, \mathrm{CO}_{2}: \sim 1 \%\right)$ [5] gas as well as biogas $\left(\mathrm{CH}_{4}: \sim 50 \%, \mathrm{CO}_{2}: \sim 50 \%\right)$ [6]. Therefore, how to selectively capture $\mathrm{CO}_{2}$ in a wide range of gas components is a big challenge and is considered as one of seven major challenges in the field of separation processes within chemical engineering [7].

Various $\mathrm{CO}_{2}$ capture technologies, including absorption, adsorption, cryogenics, and membranes, have been developed [8,9]. Currently, the benchmark industrially demonstrated process for 
post-combustion $\mathrm{CO}_{2}$ capture technology from power plants is amines solvent-based absorption. However, high energy is required in the regeneration process and the corrosive and volatile nature of the amines also presents problems $[10,11]$. Physisorption of $\mathrm{CO}_{2}$ into microporous materials has been widely studied in recent years. The heat of adsorption of $\mathrm{CO}_{2}$ onto porous sorbents is normally less than $50 \mathrm{~kJ} \mathrm{~mol}^{-1}$ which is much smaller than chemisorption, and thus, the regeneration process has low-energy consumption and is environment-friendly [12,13]. A variety of microporous adsorbents including zeolite, activated carbons, metal-organic frameworks (MOFs) [14], and covalent-organic frameworks (COFs) $[15,16]$ have been developed. Among these porous materials, MOFs have attracted significant attention owing to their enormous variety of interesting structural topologies and wide range of potential applications. These are constructed from metal ions as nodes and multidentate organic ligands as linkers. Adsorption and further separation of $\mathrm{CO}_{2}$ in MOFs have been intensely studied [12,17-19], and a variety of strategies of metal open-site, amino-functionalization, and pore size optimization have been successfully demonstrated. However, the major drawbacks of stabilities and robust fabrication limited the further application of MOFs. UiO-66 is a metal-organic skeleton material containing $\mathrm{Zr}$ developed by the University of Oslo in Norway in 2008 [20]. UiO-66 and its $-\mathrm{NH}_{2}$ modified derivates are considered good adsorbents for molecule and ion adsorption in gas [21] and solution [22,23] due to their excellent stability in heat and water [24]. In particular, UiO-66- $\mathrm{NH}_{2}$, which contains amine pendant groups on benzene dicarboxylate linkers, has showed the potential for selective adsorption of $\mathrm{CO}_{2}$ over $\mathrm{N}_{2}$ or $\mathrm{CH}_{4}$ when simply comparing the gas adsorption performance under conditions of equilibrium [25-27]. UiO-66- $\mathrm{NH}_{2}$ nanocrystals were also used as filler to prepare a mixed-matrix membrane for $\mathrm{CO}_{2} / \mathrm{N}_{2}$ [28] and $\mathrm{CO}_{2} / \mathrm{CH}_{4}$ [29] separation. However, the carbon capture from the mixture gas is a non-equilibrium process; the dynamic research of $\mathrm{CO}_{2}, \mathrm{CH}_{4}$ and $\mathrm{N}_{2}$ selective adsorption and separation at both the experimental and the theoretical level requires more attention, which is critical to develop sustainable carbon capture technology.

In this work, we synthesized $\mathrm{UiO}-66$ and $\mathrm{UiO}-66-\mathrm{NH}_{2}$ nanocrystals in a fast and easy way. UiO-66 and $\mathrm{UiO}-66-\mathrm{NH}_{2}$ displayed $\mathrm{CO}_{2}$ selective adsorption ability over $\mathrm{N}_{2}$ and $\mathrm{CH}_{4}$. The ideal selectivity of $\mathrm{CO}_{2} / \mathrm{N}_{2}$ and $\mathrm{CO}_{2} / \mathrm{CH}_{4}$ in UiO-66- $\mathrm{NH}_{2}$ was calculated to be 20 and 7 under $298 \mathrm{~K}$, respectively. The carbon capture from flue gas and raw natural gas was performed in a UiO-66- $\mathrm{NH}_{2}$ packed column by breakthrough experiments. $\mathrm{CO}_{2}$ molecules can be effectively removed with the selective factor of seven $\left(\mathrm{CO}_{2} / \mathrm{N}_{2}, 15 / 85\right.$ in volume $)$ and two $\left(\mathrm{CO}_{2} / \mathrm{CH}_{4}, 10 / 90\right.$ in volume), respectively. In addition, the separation process was further simulated by theoretical calculation to recover the binding energies of gas molecules and prefer gas adsorption abilities of $\mathrm{UiO}-66-\mathrm{NH}_{2}$.

\section{Results}

\subsection{Synthesis and Characterization}

UiO-66 and UiO-66- $\mathrm{NH}_{2}$ were synthesized in a convenient process, in which the nanocrystals were prepared in a short time (total $2.5 \mathrm{~h}$ ) under ambient pressure without using pressure autoclave. Typically, Zirconium tetrachloride $\left(\mathrm{ZrCl}_{4}\right)$, hydrochloric acid $(\mathrm{HCl}, 37 \mathrm{wt} \%)$, terephthalic acid, and $\mathrm{N}, \mathrm{N}$-Dimethylformamide (DMF) were placed in a glass vial $(100 \mathrm{~mL})$ and vigorously stirred for $30 \mathrm{~min}$ at $80{ }^{\circ} \mathrm{C}$. After centrifugation, washing, and drying, $\mathrm{UiO}-66$ and $\mathrm{UiO}-66-\mathrm{NH}_{2}$ particles were then obtained.

The morphologies of $\mathrm{UiO}-66$ and $\mathrm{UiO}-66-\mathrm{NH}_{2}$ crystals were firstly characterized through scanning electron microscopy (SEM) and transmission electron microscopy (TEM). Figure 1a shows the morphology of UiO-66, where the typical particle size in the range of 100-200 nm was found. Synthesized UiO-66- $\mathrm{NH}_{2}$ possessed a smaller particle size with the typical size less than $100 \mathrm{~nm}$ (Figure 1b). Furthermore, the TEM images also showed that the UiO-66 (Figure 1c) and UiO-66- $\mathrm{NH}_{2}$ (Figure 1d) particles possess an irregular shape with the mean particle size around $200 \mathrm{~nm}$ (UiO-66) and approximate $100 \mathrm{~nm}\left(\mathrm{UiO}-66-\mathrm{NH}_{2}\right)$, respectively, and this was mutually verified by SEM results. The energy-dispersive X-ray spectroscopy (EDS) mapping was employed to investigate the elements' 
distribution. As indicated in Figure 1e,f, the elements $\mathrm{Zr}$ and $\mathrm{O}$ uniformly spread over the particles, while the element $\mathrm{N}$ was also founded from $\mathrm{UiO}-66-\mathrm{NH}_{2}$ which is derived from the $-\mathrm{NH}_{2}$ group of the ligand (2-aminoterephtalic acid).
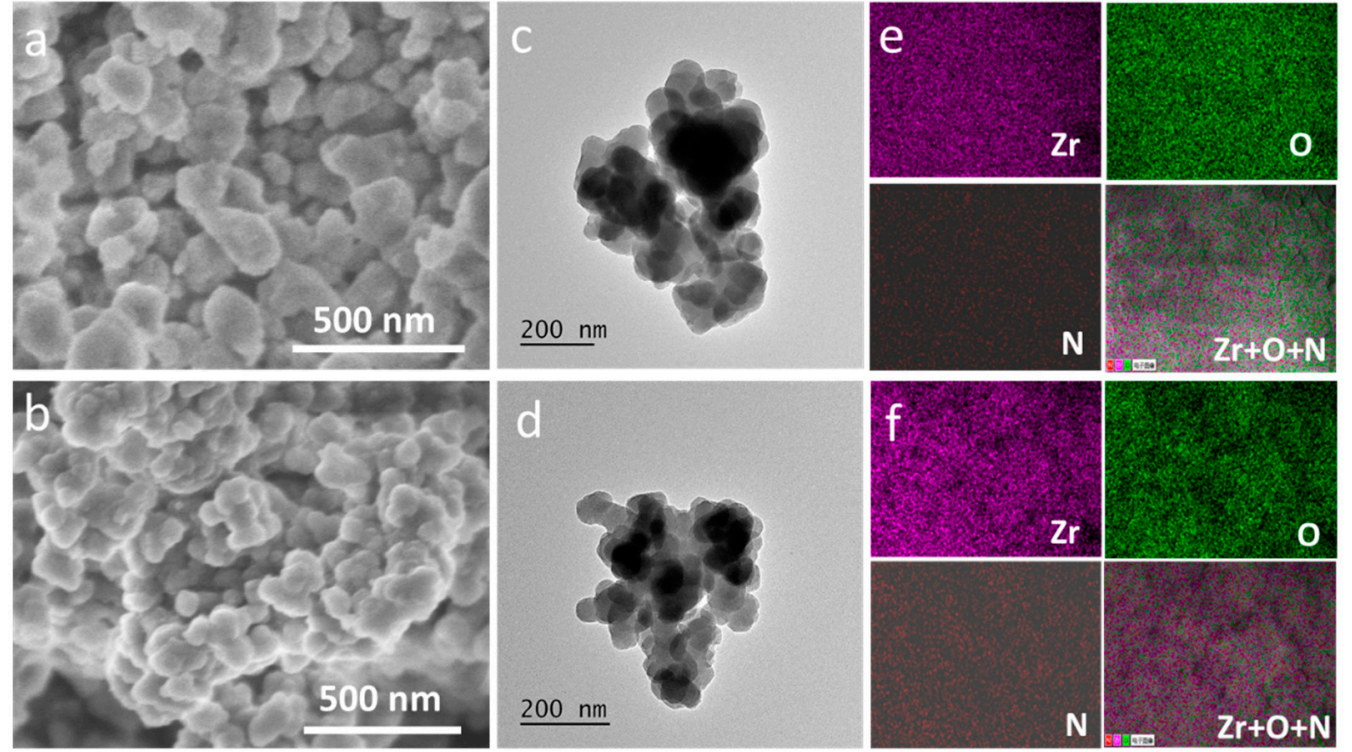

Figure 1. The SEM (a), TEM (c) and EDS (e) mapping images of UiO-66; the SEM (b), TEM (d) and EDS (f) mapping images of $\mathrm{UiO}-66-\mathrm{NH}_{2}$.

The crystal phase was then examined by X-ray powder diffraction (XRD). Figure 2a shows the major diffraction patterns of $\mathrm{UiO}-66$ and $\mathrm{UiO}-66-\mathrm{NH}_{2}$, where the peaks were well consistent with the simulated pattern of UiO-66 reported previously [20]. However, the as-synthesized UiO-66 and UiO-66- $\mathrm{NH}_{2}$ particles exhibited broad peaks with low intensity, suggesting that some disorder and therefore large number of defects would exist in UiO-66 and UiO-66- $\mathrm{NH}_{2}$ [30,31]. Recent studies have shown that defects in MOFs provide a positive influence on catalysis, adsorption, and proton conductivity [32]. Fourier-transform infrared spectroscopy (FTIR) spectra in Figure 2b shows the chemical information of $\mathrm{UiO}-66$ and $\mathrm{UiO}-66-\mathrm{NH}_{2}$. They have similar vibrational peaks in the FTIR spectra. The characteristic peak around $3403 \mathrm{~cm}^{-1}$ was ascribed to the vibrational mode of the $\mathrm{O}-\mathrm{H}$ group, which was related to the adsorbed water from the surface of the samples. A lot of intense peaks in the range of $1700-1200 \mathrm{~cm}^{-1}$ were derived from asymmetrical and symmetrical stretching vibrations of the carboxylate groups. The peaks at $800-600 \mathrm{~cm}^{-1}$ might be ascribed to a $\mathrm{Zr}-\mathrm{O}$ bond. Especially, the peaks of 1390 and $1264 \mathrm{~cm}^{-1}$ were attributed to the vibrational mode of the C-N band in FTIR spectra of UiO-66- $\mathrm{NH}_{2}$, which originate from the $-\mathrm{NH}_{2}$ group of ligands of UiO-66-NH 2 . We use acid-base titration to further determine the existence and quantity of defects in UiO-66 and $\mathrm{UiO}-66-\mathrm{NH}_{2}$. The titration curves for UiO-66 and UiO-66- $\mathrm{NH}_{2}$ are shown in Figure 2c. There is a slow break in the curve between the $\mathrm{pH}$ of five and seven. To better visualize the various equivalence points, the first derivative of the titration curve is further plotted. The results show the distinct equivalence points corresponding to the $\mathrm{pKa}$ values in Table 1 . These defects can be assigned to bridging-OH, acetic acid, and $\mathrm{Zr}-\mathrm{OH}_{2}$, respectively [31]. The thermal stability was also investigated by thermal gravimetric analysis (TGA) (Figure 2d), the weight loss before $100{ }^{\circ} \mathrm{C}$ was due to the removal of adsorbed small molecules from air, ca. $\mathrm{CO}_{2}$ and $\mathrm{H}_{2} \mathrm{O}$. No obvious decomposition was found before $500{ }^{\circ} \mathrm{C}$ for $\mathrm{UiO}-66$ and $300{ }^{\circ} \mathrm{C}$ for $\mathrm{UiO}-66-\mathrm{NH}_{2}$ indicating their superior stability [20]. 

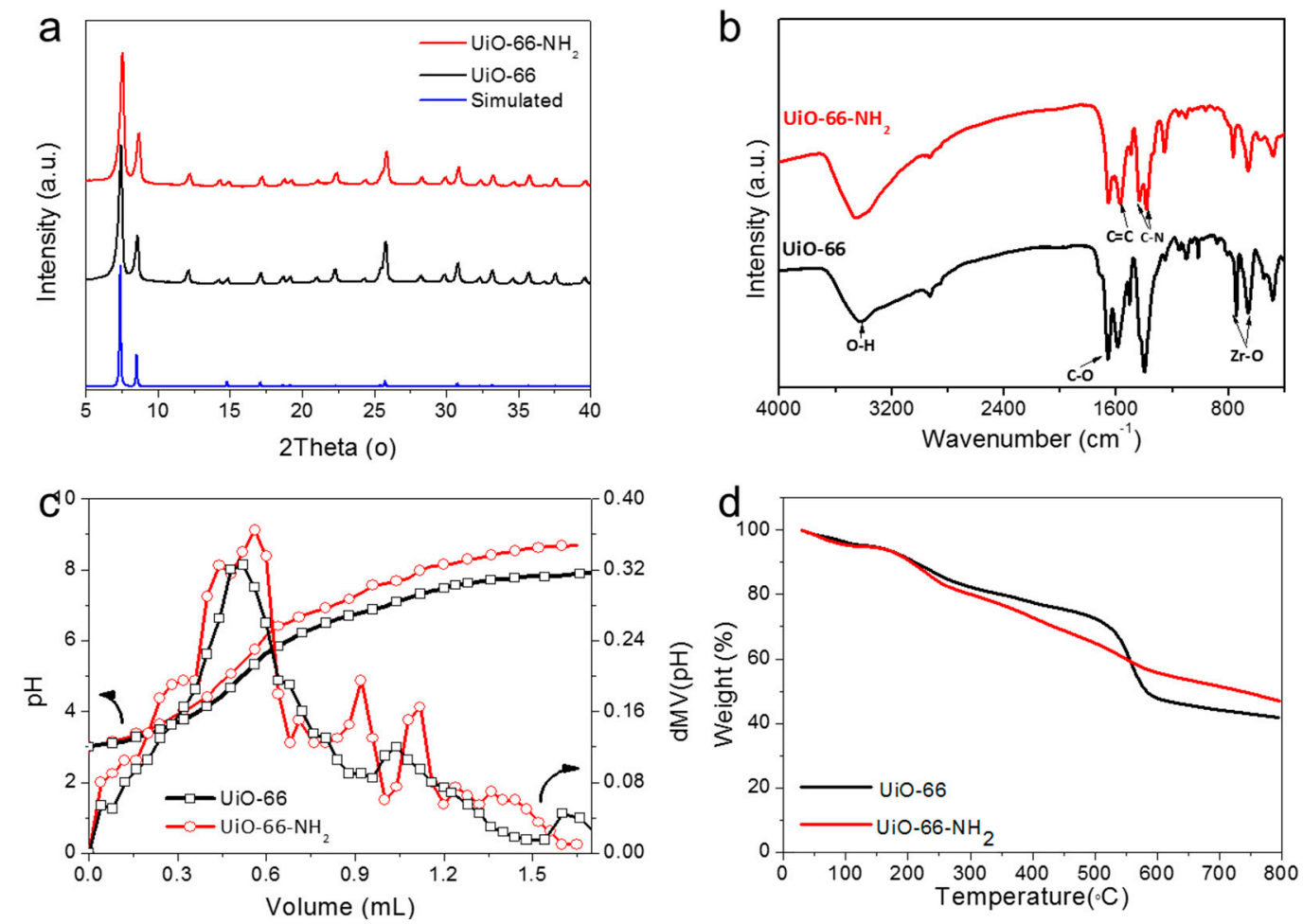

Figure 2. X-ray diffraction patterns (a), FTIR spectra (b), acid-base titration curves (c), and TGA (d) curves of UiO-66 and UiO-66- $\mathrm{NH}_{2}$.

Table 1. Calculated pKa's and corresponding equivalence volumes for UiO-66 and $\mathrm{UiO}-66-\mathrm{NH}_{2}$ samples that were analyzed by acid-base titration.

\begin{tabular}{ccccccc}
\hline \multirow{2}{*}{ MOFs } & \multicolumn{2}{c}{ Bridging-OH } & \multicolumn{2}{c}{ Acetate } & \multicolumn{2}{c}{ Zr-OH } \\
\cline { 2 - 7 } & $\mathbf{p K a}$ & Equi. vol. (mL) & pKa & Equi. vol. (mL) & pKa & Equi. vol. (mL) \\
\hline UiO-66 & 3.47 & 0.52 & 5.04 & 1.04 & 6.47 & 1.60 \\
UiO-66-NH ${ }_{2}$ & 3.82 & 0.56 & 4.92 & 0.92 & 5.76 & 1.12 \\
\hline
\end{tabular}

\subsection{Pore Structure and Gas Selective Adsorption}

The textural characteristics (surface areas, pore size and pore volume) of UiO-66 and UiO-66- $\mathrm{NH}_{2}$ nanocrystals are evaluated by $\mathrm{N}_{2}$ adsorption and desorption analysis at $77 \mathrm{~K}$. The nitrogen adsorption-desorption isotherms and the pore size distribution of UiO-66 and $\mathrm{UiO}-66-\mathrm{NH}_{2}$ are shown in Figure 3. The characteristic of isotherms was in accord with type-II adsorption isotherms where the primary adsorption occurred at low relative pressures $<0.1$ indicated the formation of a highly microporous material with the possibility of a narrow pore size distribution of UiO-66 and UiO-66- $\mathrm{NH}_{2}$. The adsorption curve climbed rapidly at $\mathrm{P} / \mathrm{P}_{0}$ values greater than 0.95 indicating the capillary condensation derived from the aggregation of nanoparticles or defects. The results showed that UiO-66 and UiO-66- $\mathrm{NH}_{2}$ had a large Brunauer-Emmett-Teller (BET) surface area of 1308 and $1104 \mathrm{~m}^{2} \mathrm{~g}^{-1}$, respectively, and it was in good agreement with previously reported UiO-66 structures that contain defects $[31,33]$. The pore distributions of UiO-66 and UiO-66- $\mathrm{NH}_{2}$ were further investigated through the Nonlocal Density Functional Theory (NLDFT) method based on the adsorption data. The bimodal pore distributions of ultramicropores $(<0.7 \mathrm{~nm})$ and supermicropores $(0.7-2 \mathrm{~nm})$ were probed as displayed in Figure $3 \mathrm{~b}$. Moreover, the pore volume was 0.533 (UiO-66) and 0.462 (UiO-66- $\left.\mathrm{NH}_{2}\right) \mathrm{cm}^{3} \mathrm{~g}^{-1}$, respectively. These results demonstrated that the prepared UiO-66 and UiO-66- $\mathrm{NH}_{2}$ possess a high surface area in the micropore range and thus enabled a desirable adsorption capability. 

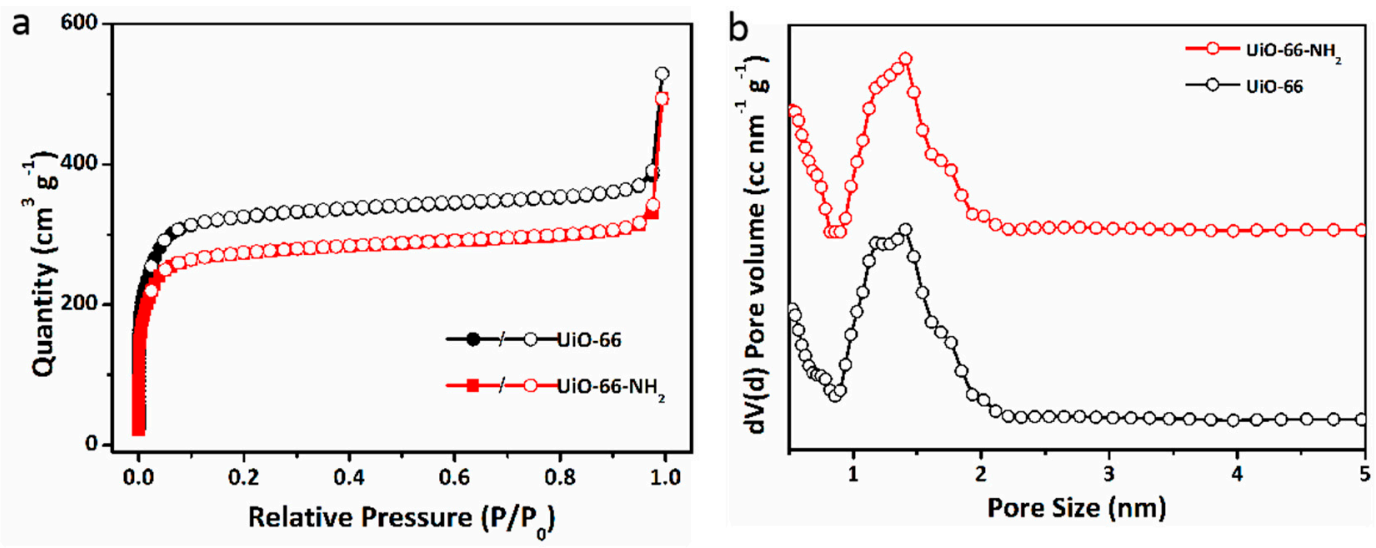

Figure 3. $\mathrm{N}_{2}$ isotherms at $77 \mathrm{~K}$ (a) and pore distribution curves (b) calculated from absorption curves by the NLDFT mode of UiO-66 and UiO-66- $\mathrm{NH}_{2}$.

With their combination of nanosized, abundant defects and a large number of micropores, UiO-66 and UiO-66- $\mathrm{NH}_{2}$ demonstrated that they have great potential in the field of gas adsorption and separation. The $\mathrm{CO}_{2}, \mathrm{CH}_{4}$ and $\mathrm{N}_{2}$ adsorption-desorption curves are given in Figure 4, where the isotherms are recorded under the two temperatures of $273 \mathrm{~K}$ and $298 \mathrm{~K}$, respectively. UiO-66 and UiO-66- $\mathrm{NH}_{2}$ exhibited excellent adsorption performance for $\mathrm{CO}_{2}$ at different temperatures. As shown in Figure 4, the $\mathrm{CO}_{2}, \mathrm{CH}_{4}$ and $\mathrm{N}_{2}$ equilibrium adsorption capacities of $\mathrm{UiO}-66$ were $61 \mathrm{~cm}^{3} \mathrm{~g}^{-1}, 13.6 \mathrm{~cm}^{3}$ $\mathrm{g}^{-1}$, and $2.7 \mathrm{~cm}^{3} \mathrm{~g}^{-1}$ at $273 \mathrm{~K}$ and $100 \mathrm{kPa}$, respectively. For $298 \mathrm{~K}$ and $100 \mathrm{kPa}$, the uptake capacities of $\mathrm{CO}_{2}, \mathrm{CH}_{4}$, and $\mathrm{N}_{2}$ were $33.4 \mathrm{~cm}^{3} \mathrm{~g}^{-1}, 8.1 \mathrm{~cm}^{3} \mathrm{~g}^{-1}$, and $3.1 \mathrm{~cm}^{3} \mathrm{~g}^{-1}$, respectively. The enhancement gas adsorption abilities were found from UiO-66- $\mathrm{NH}_{2}$. The $\mathrm{CO}_{2}, \mathrm{CH}_{4}$, and $\mathrm{N}_{2}$ equilibrium adsorption capacity of $\mathrm{UiO}-66-\mathrm{NH}_{2}$ were $68 \mathrm{~cm}^{3} \mathrm{~g}^{-1}, 13.9 \mathrm{~cm}^{3} \mathrm{~g}^{-1}$, and $2.8 \mathrm{~cm}^{3} \mathrm{~g}^{-1}$ at $273 \mathrm{~K}$ and $100 \mathrm{kPa}$, respectively. And they were $37.6,8.1$, and $2.9 \mathrm{~cm}^{3} \mathrm{~g}^{-1}$ at $298 \mathrm{~K}$ and $100 \mathrm{kPa}$. UiO-66- $\mathrm{NH}_{2}$ and UiO-66 have moderate $\mathrm{CO}_{2}$ uptakes which are comparable with MIL-100(Cr) (50) [34], UiO-66 (38) [27], MAC-4 (37.2) [35], IRMOF-1 (27.3) [36], and MOF-177 (19.8) [36] at atmosphere condition.
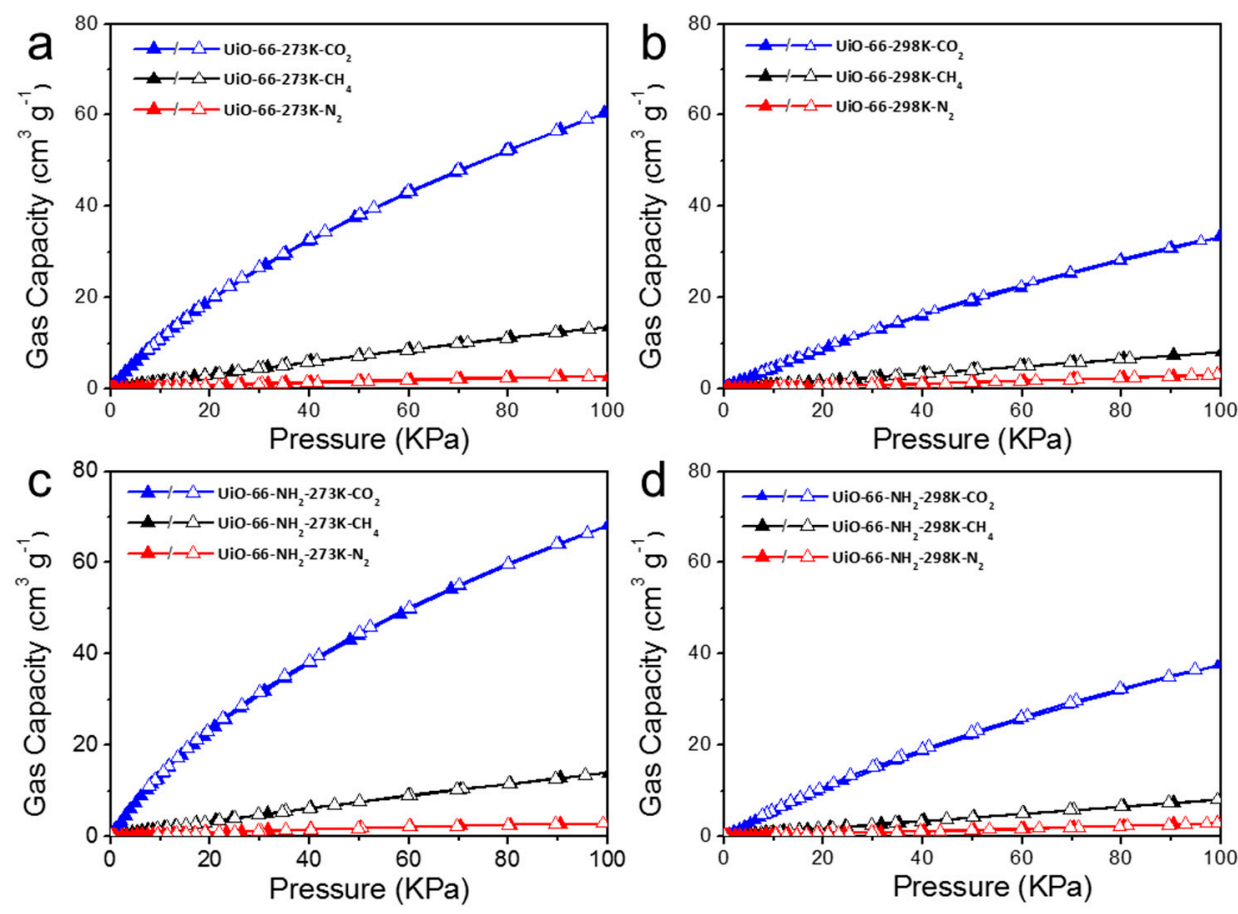

Figure 4. $\mathrm{CO}_{2}, \mathrm{CH}_{4}$, and $\mathrm{N}_{2}$ adsorption-desorption isotherms of $\mathrm{UiO}-66$ at $273 \mathrm{~K}(\mathbf{a})$ and $298 \mathrm{~K}$ (b); $\mathrm{UiO}-66-\mathrm{NH}_{2}$ at $273 \mathrm{~K}(\mathbf{c})$ and $298 \mathrm{~K}(\mathbf{d})$. 
The $\mathrm{CO}_{2}$ capacity was further normalized to the pore volume to recover the affection of chemical components of UiO-66 and $\mathrm{UiO}-66-\mathrm{NH}_{2}$. As indicated in Figure 5, UiO-66- $\mathrm{NH}_{2}$ has obvious larger normalized $\mathrm{CO}_{2}$ adsorption values than $\mathrm{UiO}-66$. This phenomenon showed that the $-\mathrm{NH}_{2}$ group of ligands in UiO-66- $\mathrm{NH}_{2}$ may contribute more to the $\mathrm{CO}_{2}$ molecule adsorption sites, and this conclusion coincides with Ethiraj's conclusion [37]. More importantly, UiO-66 and UiO-66- $\mathrm{NH}_{2}$ display apparent higher $\mathrm{CO}_{2}$ adsorption capacity than $\mathrm{CH}_{4}$ and $\mathrm{N}_{2}$ under the same temperatures and pressures, meaning that it has potential to remove $\mathrm{CO}_{2}$ from $\mathrm{CH}_{4}$ and $\mathrm{N}_{2}$ by selective adsorption.

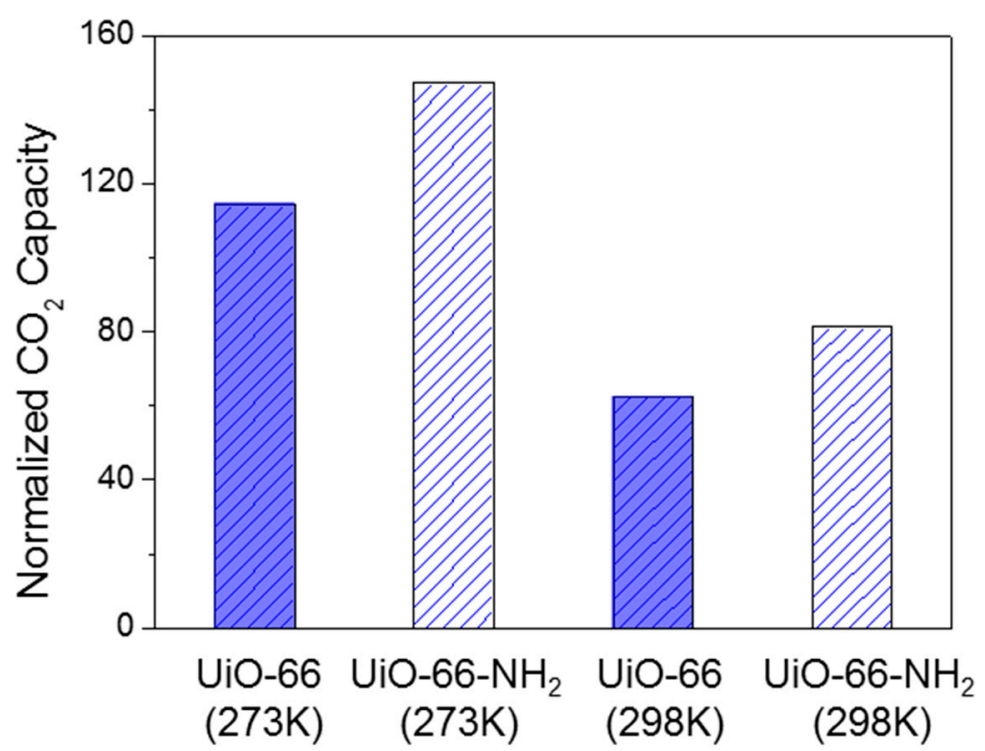

Figure 5. The normalized $\mathrm{CO}_{2}$ capacities of $\mathrm{UiO}-66$ and $\mathrm{UiO}-66-\mathrm{NH}_{2}$.

\subsection{Dynamic Separation of Flue Gas and Natural Gas}

The gas selective separation abilities of $\mathrm{UiO}-66$ and $\mathrm{UiO}-66-\mathrm{NH}_{2}$ were firstly evaluated through ideal adsorbed solution theory (IAST), which is widely used to estimate the potential of gas separation of porous materials based on single gas equilibrium adsorption curves [38]. Single-component isotherms of $\mathrm{CO}_{2} / \mathrm{N}_{2}$ (15/85 in volume) and $\mathrm{CO}_{2} / \mathrm{CH}_{4}$ (10/90 in volume) at $298 \mathrm{~K}$ were fitted, where the component was the typical composite of flue gas $\left(\mathrm{CO}_{2}\right.$ and $\left.\mathrm{N}_{2}\right)$ and raw natural gas $\left(\mathrm{CO}_{2}\right.$ and $\left.\mathrm{CH}_{4}\right)$. As shown in Figure 6, the adsorption selectivity of $\mathrm{CO}_{2} / \mathrm{N}_{2}$ were calculated to be about 16 (UiO-66) and 20 $\left(\mathrm{UiO}-66-\mathrm{NH}_{2}\right)$ at a pressure of $100 \mathrm{kPa}$ and $298 \mathrm{~K}$, respectively, which is comparable with UiO-66 (17.8) [25] and MOF-505 (27.8) [39]. The $\mathrm{CO}_{2} / \mathrm{CH}_{4}$ selectivity was about $6(\mathrm{UiO}-66)$ and $7\left(\mathrm{UiO}-66-\mathrm{NH}_{2}\right)$ at the same condition, respectively, which is at the same level with MIL-100(Cr) (8) [34], MOF-505 (7.6) [39], and MAF-66 (5.8) [40]. The IAST results indicated the feasibility of UiO-66- $\mathrm{NH}_{2}$ for practical application in the separation of $\mathrm{CO}_{2} / \mathrm{N}_{2}$ and $\mathrm{CO}_{2} / \mathrm{CH}_{4}$.

To evaluate the potential for real separation of the gas mixture of $\mathrm{CO}_{2} / \mathrm{N}_{2}$ and $\mathrm{CO}_{2} / \mathrm{CH}_{4}$ of UiO-66- $\mathrm{NH}_{2}$, the breakthrough experiments were carried out with binary mixtures of $\mathrm{CO}_{2} / \mathrm{N}_{2}(15: 85$, $v / v)$ and $\mathrm{CO}_{2} / \mathrm{CH}_{4}(10: 90, v / v)$ on a home-made column breakthrough setup (supporting information) which is the typical composition of flue gas and nature gas. As shown in Figure $6 \mathrm{~b}$, the results suggest the high-efficiency separation of $\mathrm{N}_{2}$ from $15: 85 \mathrm{CO}_{2} / \mathrm{N}_{2}$ by flowing the mixture gas over a packed column of UiO-66- $\mathrm{NH}_{2}$. It could be clearly observed that the $\mathrm{N}_{2}$ first breakthrough was at $7 \mathrm{~s}$, while the $\mathrm{CO}_{2}$ could not be detected before its breakthrough point at $49 \mathrm{~s}$. The separation factor was calculated to be seven following the calculation procedure provided in the supporting information. As shown in Figure $6 \mathrm{~d}$, the dynamic separation experiment of $\mathrm{CO}_{2} / \mathrm{CH}_{4}$ mixed gas (10/90 in volume ration; flow speed of $2 \mathrm{~mL} \mathrm{~min}^{-1}$ ) was also examined under room temperature ( $\left.298 \mathrm{~K}\right)$. The breakthrough curves can be divided into three segments based on their adsorption characteristics. The net breakthrough times (with the dead time deducted) of $\mathrm{CO}_{2}$ and $\mathrm{CH}_{4}$ were 114 and $226 \mathrm{~s}$, respectively, giving a 
$\mathrm{CO}_{2} / \mathrm{CH}_{4}(10 / 90)$ separation factor of about two. Therefore, the ability of selective adsorption and further remove $\mathrm{CO}_{2}$ from flue gas and natural gas of $\mathrm{UiO}-66-\mathrm{NH}_{2}$ has been demonstrated.
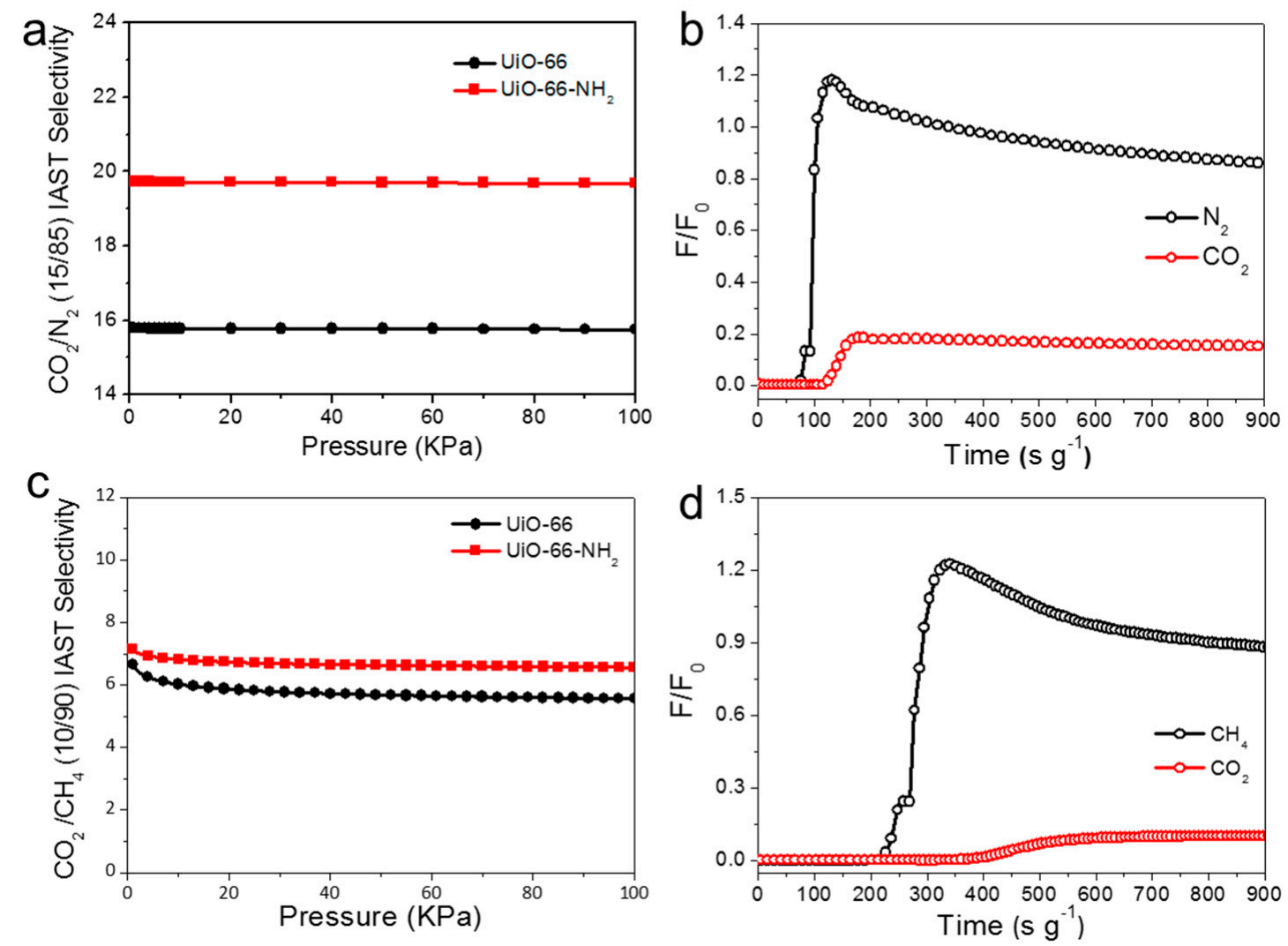

Figure 6. The IAST (a) and breakthrough separation curves (b) of $\mathrm{CO}_{2} / \mathrm{CH}_{4}$ (10/90 in volume ration) of UiO-66 and UiO-66- $\mathrm{NH}_{2}$; the IAST (c) and breakthrough separation (d) curves (s) of $\mathrm{CO}_{2} / \mathrm{N}_{2}(15 / 85$ in volume ration) of $\mathrm{UiO}-66$ and $\mathrm{UiO}-66-\mathrm{NH}_{2}$.

\subsection{Monte Carlo Simulation of Gas Selective Adsorption}

A simple $\mathrm{MC}$ simulation was further carried out to analyze the distribution position and adsorption energy of $\mathrm{CO}_{2}, \mathrm{~N}_{2}$ and $\mathrm{CH}_{4}$ in UiO-66- $\mathrm{NH}_{2}$. The simulation results showed that $\mathrm{CO}_{2}, \mathrm{~N}_{2}$, and $\mathrm{CH}_{4}$ molecules were mainly distributed in the cage surrounded by three ligands of $\mathrm{UiO}-66-\mathrm{NH}_{2}$ (Figure 7a). At the initial state, one $\mathrm{CO}_{2}$ molecule and seven $\mathrm{N}_{2}$ or $\mathrm{CH}_{4}$ molecules were placed in the cage to follow the chemical components of flue gas and raw natural gas, respectively. The optimized structures for $\mathrm{CO}_{2}$ and $\mathrm{N}_{2}$ or $\mathrm{CO}_{2}$ and $\mathrm{CH}_{4}$ are shown in Figure $7 \mathrm{~b}, \mathrm{c}$, respectively. Small molecules were found to be located in the middle of the triangle area which implies that the weak interactions may rest between small molecules and UiO-66- $\mathrm{NH}_{2}$. To prove these weak intermolecular interactions, an Independent Gradient Model [41] was carried out for those two structures in Figure 7b,c. The scatter plots for the $\delta$ function versus the $\operatorname{sign}\left(\lambda_{2}\right) \rho$ including intermolecular (red area) and intramolecular (black area) interactions were shown in Figure $7 \mathrm{~d}, \mathrm{e}$, where the $\operatorname{sign}\left(\lambda_{2}\right) \rho$ is the sign of the second largest eigenvalue $\lambda_{2}$ of the electron-density Hessian matrix multiplied by the electron density. It could be seen that the electron density of intermolecular interaction is not very large, but not very close to zero either. Based on this we can speculate that the intermolecular interactions in those two systems are weak interactions. The adsorption energy for $\mathrm{CO}_{2}, \mathrm{~N}_{2}$, and $\mathrm{CH}_{4}$ are estimated to be $0.32,0.19$, and $0.20 \mathrm{eV}$, respectively. It can be speculated that the $\mathrm{CO}_{2}$ and $\mathrm{CH}_{4}$ or $\mathrm{CO}_{2}$ and $\mathrm{N}_{2}$ mixed gases can be effectively separated by this MOF material, which is consistent with the experimental results. 


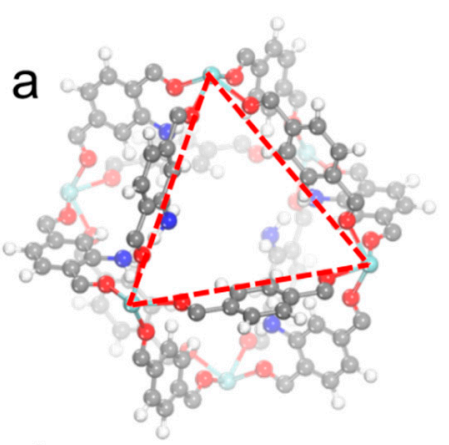

d

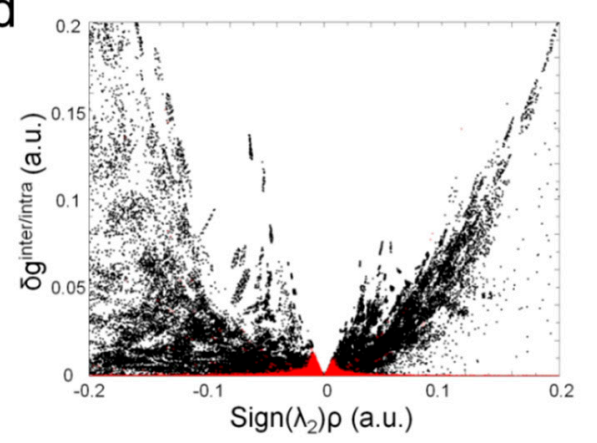

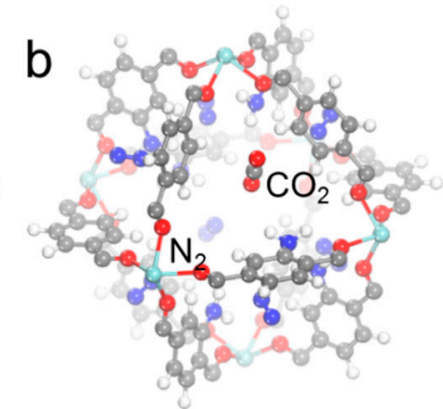
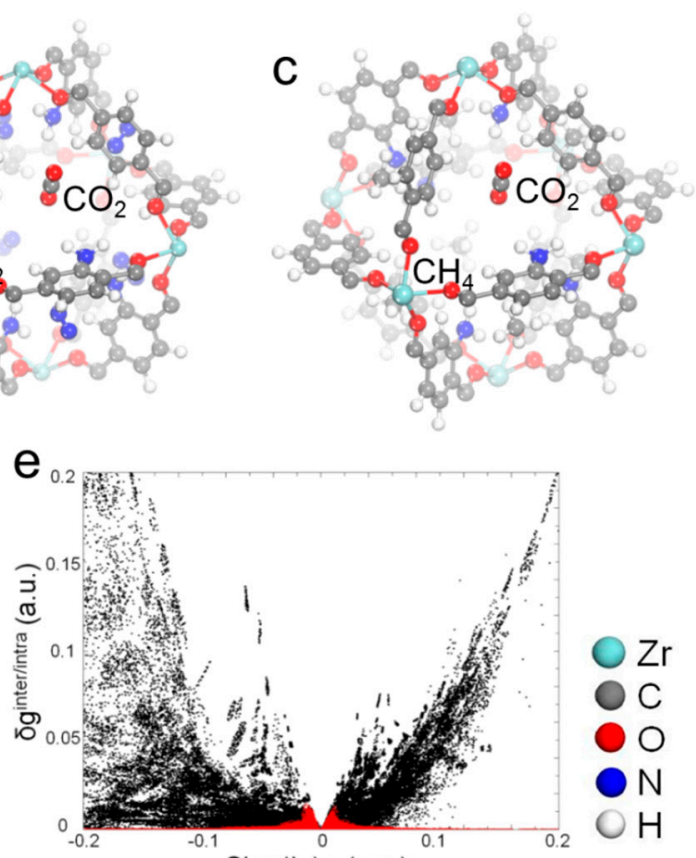

$\operatorname{Sign}\left(\lambda_{2}\right) \rho$ (a.u.)

Figure 7. Optimized structures and intermolecular interactions between $\mathrm{CO}_{2}, \mathrm{~N}_{2}$ and $\mathrm{CH}_{4}$. Stable porous cage structure of $\mathrm{UiO}-66-\mathrm{NH}_{2}(\mathbf{a})$, stable adsorption structure for $\mathrm{CO}_{2}$ and $\mathrm{N}_{2}$ adsorption in UiO-66- $\mathrm{NH}_{2}(\mathbf{b})$, stable adsorption structure for $\mathrm{CO}_{2}$ and $\mathrm{CH}_{4}$ adsorption in UiO-66- $\mathrm{NH}_{2}(\mathbf{c})$, scatter plot for $\delta$ function versus $\operatorname{sign}\left(\lambda_{2}\right) \rho$ of $\mathrm{CO}_{2}$ and $\mathrm{N}_{2}(\mathbf{d})$ and $\mathrm{CO}_{2}$ and $\mathrm{CH}_{4}(\mathbf{e})$ adsorption in $\mathrm{UiO}-66-\mathrm{NH}_{2}$.

\section{Materials and Methods}

\subsection{Chemicals and Characterizations}

The chemicals used were Zirconium chloride $\left(\mathrm{ZrCl}_{4}, \geq 99.5 \%\right)$, terephthalic acid (99\%), 2-aminoterephtalic acid (99\%), hydrochloric acid ( $\mathrm{HCl}, 5 \%)$, and $N, N$-Dimethylformamide (DMF). All chemicals were used as received without further purification. Powder X-ray diffraction patterns (XRD) were recorded on a Rigaku Ultima Iv X-ray diffractometer $(\mathrm{Cu} \mathrm{K} \alpha, \lambda=1.5406 \AA$, Rigaku, Tokyo, Japan, ) at a scan rate of $10^{\circ} \mathrm{min}^{-1}$ in the $2 \theta$ range from $3^{\circ}$ to $80^{\circ}$. Fourier transform infrared spectroscopy (FTIR) spectra were measured using Frontier MidIR FTIR (PerkinElmer, Waltham, MA, USA) with the $\mathrm{KBr}$ pellet technique in the range $400-4000 \mathrm{~cm}^{-1}$. The morphologies of the materials were observed using a Verios 460L scanning electron microscope (SEM, FEI, Hillsboro, OR, USA) and a Tecnai G2 Spirit TWIN transmission electron microscope (TEM, FEI, Hillsboro).

\subsection{Synthesis of UiO-66 and $\mathrm{UiO}-66-\mathrm{NH}_{2}$}

A total of $0.625 \mathrm{~g}$ of $\mathrm{ZrCl}_{4}$ and $5 \mathrm{~mL}$ of $37 \% \mathrm{HCl}$ aqueous solution were mixed and dissolved in 10 $\mathrm{mL}$ of DMF. After $30 \mathrm{~min}$ of ultrasonication, $0.615 \mathrm{~g}$ of terephthalic acid dissolved in $50 \mathrm{~mL}$ of DMF was added to the former solution of $\mathrm{ZrCl}_{4}$ and $\mathrm{HCl}$, and the whole solution was further sonicated by using a batch sonication (Kunshan Ultrasonic Instruments Co., Ltd., KQ-100, Kunshan, Jiangsu, China) with the output power of $100 \mathrm{~W}$ and the frequency of $40 \mathrm{kHz}$ for the next $30 \mathrm{~min}$. The solution was then kept in a $100 \mathrm{~mL}$ glass vial at $80{ }^{\circ} \mathrm{C}$ statically without stirring or ultrasonicating at $80{ }^{\circ} \mathrm{C}$ for $2 \mathrm{~h}$. UiO-66- $\mathrm{NH}_{2}$ was prepared following the same process except that 2-aminoterephtalic acid was used to replace the terephthalic acid.

\subsection{Acid-Base Titrations}

A total of $40 \mathrm{mg}$ of sample (activated for $12 \mathrm{~h}$ at $150{ }^{\circ} \mathrm{C}$ ) was added to a $100 \mathrm{~mL}$ beaker. An equivalent volume of a $0.01 \mathrm{M} \mathrm{NaNO}_{3}$ solution was added and allowed to equilibrate for $18 \mathrm{~h}$. 
Preceding each titration, a stir bar was added to the beaker and the $\mathrm{pH}$ was adjusted to a value of 3.00 with $0.1 \mathrm{M} \mathrm{HCl}$. Following this, the solution was titrated with $0.1 \mathrm{M} \mathrm{NaOH}$ of solution (adding 0.04 $\mathrm{mL} \mathrm{NaOH}$ solution at a time and stirring evenly) with a $\mathrm{pH}$ value of 8 .

\subsection{Gas Adsorption Measurement}

The $\mathrm{N}_{2}$ sorption isotherms at $77 \mathrm{~K}$ and the gas adsorption isotherms of $\mathrm{CO}_{2}, \mathrm{CH}_{4}$, and $\mathrm{N}_{2}$ at two different temperatures (273 and $298 \mathrm{~K}$ ) were measured by using a Autosorb-iq3 surface area and porosimeter analyzer (Quantachrome, Boynton Beach, FL, USA). The temperatures (273 and 298 K) were controlled by means of a circulating bath. The samples were degassed at $473 \mathrm{~K}$ for $10 \mathrm{~h}$ under a vacuum of $10^{-5} \mathrm{mmHg}$ before the measurements. The pore size distributions and micropore surface areas were determined using the nonlocal density function theory (NLDFT) method. Gases with a high purity of over $99.995 \%$ were used.

\subsection{Breakthrough Experiments}

The breakthrough experiments of flue gas and natural gas separation were conducted in a home-made apparatus as illustrated in our previous reports [42,43].

The absolute adsorbed amount of gas $i\left(q_{i}\right)$ was calculated from the breakthrough curve by the equation:

$$
q_{i}=\frac{F_{i} \times t_{0}-V_{\text {dead }}-\int_{0}^{t_{o}} F_{e} \Delta t}{m}
$$

where $F_{i}=$ influent flow rate of the specific gas $\left(\mathrm{cm}^{3} \mathrm{~min}^{-1}\right) ; t_{0}=$ adsorption time $(\mathrm{min}) ; V_{\text {dead }}=$ dead volume of the system $\left(\mathrm{cm}^{3}\right) ; F_{e}=$ effluent flow rate of the specific gas $\left(\mathrm{cm}^{3} \mathrm{~min}^{-1}\right) ; m=$ mass of the sorbent $(\mathrm{g})$.

The selectivity of the breakthrough experiment is defined as $\alpha=\left(\mathrm{q}_{1} / \mathrm{y}_{1}\right) /\left(\mathrm{q}_{2} / \mathrm{y}_{2}\right)$, where $\mathrm{y}_{\mathrm{i}}$ is the mole fraction of gas $i$ in the gas mixture.

\subsection{DFT Calculations}

Monte Carlo (MC) simulations are carried out with the adsorption locator module with the universal force field [44]. All the geometric optimization calculations were performed using the generalized gradient approximation (GGA) with the Perdew-Burke-Ernzerhof (PBE) functional [45] as implemented in the all-electron $\mathrm{DMol}^{3}$ code $[46,47]$. The double numerical plus polarization (DNP) basis set was used throughout the calculations. The convergence criteria were set to be $2 \times 10^{-5} \mathrm{Ha}_{\text {, }}$ $0.004 \mathrm{Ha} \AA^{-1}$, and $0.005 \AA$ for the energy, the force, and the displacement convergences, respectively. A self-consistent field (SCF) density convergence with a threshold value of $1 \times 10^{-5} \mathrm{Ha}$ was specified. Independent Gradient Model analysis were carried out using Multiwfn software [48]. A complete MOF channel structure was cut-off from the single-crystal structure of UiO-66. All dangling bonds in the MOF structure ( $\mathrm{Zr}$ atoms) were saturated by hydroxy groups.

\section{Conclusions}

In summary, we synthesized crystals of $\mathrm{UiO}-66$ and $\mathrm{UiO}-66-\mathrm{NH}_{2}$ in nano-size with a high surface area and abundant defects. $\mathrm{UiO}-66$ and $\mathrm{UiO}-66-\mathrm{NH}_{2}$ have selective gas adsorption ability of $\mathrm{CO}_{2}$ over $\mathrm{CH}_{4}$ and $\mathrm{N}_{2}$. The pure $\mathrm{N}_{2}$ and $\mathrm{CH}_{4}$ can be obtained from the simulated flue gas $\left(\mathrm{CO}_{2} / \mathrm{N}_{2}, 15 / 85\right)$ and from raw natural gas $\left(\mathrm{CO}_{2} / \mathrm{CH}_{4}, 10 / 90\right)$ by a breakthrough operation, respectively. Especially, the separation factors of seven $\left(\mathrm{CO}_{2} / \mathrm{N}_{2}\right)$ and two $\left(\mathrm{CO}_{2} / \mathrm{CH}_{4}\right)$ were calculated from UiO-66-NH indicating the potential applications for green separation. The results of $\mathrm{MC}$ simulation showed that $\mathrm{CO}_{2}$ displayed preferential adsorption energy over $\mathrm{N}_{2}$ or $\mathrm{CH}_{4}$ in the gas mixture through $\mathrm{UiO}-66-\mathrm{NH}_{2}$. This dynamic study from theoretical and experimental aspects may provide an insight into the selective adsorption and separation of the gases. 
Author Contributions: Y.Z. and Y.C. conceived and designed the experiments; P.L. fabricated the materials; P.L. and D.W. analyzed the data; Y.S. performed the theoretical calculation; Y.Z. and Y.C. wrote the manuscript.

Funding: This research was funded by National Natural Science Foundation of China, grant number [21506148, 5171101212], Natural Science Foundation of Tianjin City, grant number [15JCYBJC52700, 16JCYBJC17000, 16ZXCLGX00120], the Scientific Research Program of Tianjin Municipal Education Commission, grant number [2017KJ248].

Acknowledgments: Y.Z. acknowledges support from the "Talent Program" of Tianjin University of Technology, "Youth Thousand Talents Program" and "131 Project" of Tianjin City. Y.S. acknowledge the National Supercomputing Center in Shenzhen for providing the computational resources and materials studio (version 7.0).

Conflicts of Interest: The authors declare no conflict of interest.

\section{References}

1. Davis, S.J.; Lewis, N.S.; Shaner, M.; Aggarwal, S.; Arent, D.; Azevedo, I.L.; Benson, S.M.; Bradley, T.; Brouwer, J.; Chiang, Y.-M.; et al. Net-zero emissions energy systems. Science 2018, 360, eaas9793. [CrossRef]

2. The State of Greenhouse Gases in the Atmosphere Based on Global Observations through 2016. Available online: https://meetingorganizer.copernicus.org/EGU2017/EGU2017-8824-1.pdf (accessed on 8 May 2019).

3. Sanz-Perez, E.S.; Murdock, C.R.; Didas, S.A.; Jones, C.W. Direct capture of $\mathrm{CO}_{2}$ from ambient air. Chem. Rev. 2016, 116, 11840-11876. [CrossRef] [PubMed]

4. Bui, M.; Adjiman, C.S.; Bardow, A.; Anthony, E.J.; Boston, A.; Brown, S.; Fennell, P.S.; Fuss, S.; Galindo, A.; Hackett, L.A.; et al. Carbon capture and storage (CCS): The way forward. Energy Environ. Sci. 2018, 11, 1062-1176.

5. Olajossy, A. Effective recovery of methane from coal mine methane gas by vacuum pressure swing adsorption: A pilot scale case study. Chem. Eng. Sci. 2013, 1, 46-54. [CrossRef]

6. Nanda, S.; Reddy, S.N.; Mitra, S.K.; Kozinski, J.A. The progressive routes for carbon capture and sequestration. Energy Sci. Eng. 2016, 4, 99-122. [CrossRef]

7. Sholl, D.S.; Lively, R.P. Seven chemical separations to change the world. Nature 2016, 532, 435-437. [CrossRef] [PubMed]

8. Baena-Moreno, F.M.; Rodriguez-Galan, M.; Vega, F.; Alonso-Farinas, B.; Vilches Arenas, L.F.; Navarrete, B. Carbon capture and utilization technologies: A literature review and recent advances. Energy Sources Part A 2019, 41, 1403-1433. [CrossRef]

9. Wilberforce, T.; Baroutaji, A.; Soudan, B.; Al-Alami, A.H.; Olabi, A.G. Outlook of carbon capture technology and challenges. Sci. Total Environ. 2019, 657, 56-72. [CrossRef] [PubMed]

10. Li, Y.; Wang, H.P.; Liao, C.-Y.; Zhao, X.; Hsiung, T.-L.; Liu, S.-H.; Chang, S.-G. Dual alkali solvent system for $\mathrm{CO}_{2}$ capture from flue gas. Environ. Sci. Technol. 2017, 51, 8824-8831. [CrossRef]

11. Cachaza, A.; Gomez-Diaz, D.; Montans, A.; Navaza, J.M.; Rumbo, A. Carbon dioxide chemical absorption by solvents based on diamine and amines blend. AICHE J. 2018, 64, 2702-2710. [CrossRef]

12. Yu, J.; Xie, L.-H.; Li, J.-R.; Ma, Y.; Seminario, J.M.; Balbuena, P.B. $\mathrm{CO}_{2}$ capture and separations using MOFs: Computational and experimental studies. Chem. Rev. 2017, 117, 9674-9754. [CrossRef] [PubMed]

13. Oschatz, M.; Antonietti, M. A search for selectivity to enable $\mathrm{CO}_{2}$ capture with porous adsorbents. Energy Environ. Sci. 2018, 11, 57-70. [CrossRef]

14. Li, J.-R.; Kuppler, R.J.; Zhou, H.-C. Selective gas adsorption and separation in metal-organic frameworks. Chem. Soc. Rev. 2009, 38, 1477-1504. [CrossRef] [PubMed]

15. Zou, L.; Sun, Y.; Che, S.; Yang, X.; Wang, X.; Bosch, M.; Wang, Q.; Li, H.; Smith, M.; Yuan, S.; et al. Porous organic polymers for post-combustion carbon capture. Adv. Mater. 2017, 29, 1700229. [CrossRef] [PubMed]

16. Zhu, L.; Zhang, Y.-B. Crystallization of covalent organic frameworks for gas storage applications. Molecules 2017, 22, 1149. [CrossRef] [PubMed]

17. Li, J.-R.; Ma, Y.; McCarthy, M.C.; Sculley, J.; Yu, J.; Jeong, H.-K.; Balbuena, P.B.; Zhou, H.-C. Carbon dioxide capture-related gas adsorption and separation in metal-organic frameworks. Coord. Chem. Rev. 2011, 255, 1791-1823. [CrossRef]

18. D'Amato, R.; Donnadio, A.; Carta, M.; Sangregorio, C.; Tiana, D.; Vivani, R.; Taddei, M.; Costantino, F. Water-based synthesis and enhanced $\mathrm{CO}_{2}$ capture performance of perfluorinated cerium-based metal-organic frameworks with UiO-66 and MIL-140 topology. ACS Sustainable Chem. Eng. 2019, 7, 394-402. [CrossRef] 
19. Wang, Y.; Hu, Z.; Kundu, T.; Cheng, Y.; Dong, J.; Qian, Y.; Zhai, L.; Zhao, D. Metal-organic frameworks with reduced hydrophilicity for postcombustion $\mathrm{CO}_{2}$ capture from wet flue gas. ACS Sustainable Chem. Eng. 2018, 6, 11904-11912. [CrossRef]

20. Cavka, J.H.; Jakobsen, S.; Olsbye, U.; Guillou, N.; Lamberti, C.; Bordiga, S.; Lillerud, K.P. A new zirconium inorganic building brick forming metal organic frameworks with exceptional stability. J. Am. Chem. Soc. 2008, 130, 13850-13851. [CrossRef]

21. Peterson, G.W.; Mahle, J.J.; DeCoste, J.B.; Gordon, W.O.; Rossin, J.A. Extraordinary $\mathrm{NO}_{2}$ removal by the metal-organic framework UiO-66-NH $\mathrm{NH}_{2}$. Angew. Chem. Int. Ed. 2016, 55, 6235-6238. [CrossRef] [PubMed]

22. Rapti, S.; Pournara, A.; Sarma, D.; Papadas, I.T.; Armatas, G.S.; Hassan, Y.S.; Alkordi, M.H.; Kanatzidis, M.G.; Manos, M.J. Rapid, green and inexpensive synthesis of high quality UiO-66 amino-functionalized materials with exceptional capability for removal of hexavalent chromium from industrial waste. Inorg. Chem. Front. 2016, 3, 635-644. [CrossRef]

23. Zhan, X.-Q.; Tsai, F.-C.; Xie, L.; Zhang, K.-D.; Liu, H.-L.; Ma, N.; Shi, D.; Jiang, T. Ligands-coordinated Zr-based MOF for wastewater treatment. Nanomaterials 2018, 8, 655. [CrossRef]

24. Liu, X.L.; Demir, N.K.; Wu, Z.T.; Li, K. Highly water-stable zirconium metal organic framework UiO-66 membranes supported on alumina hollow fibers for desalination. J. Am. Chem. Soc. 2015, 137, 6999-7002. [CrossRef] [PubMed]

25. Huang, A.; Wan, L.; Caro, J. Microwave-assisted synthesis of well-shaped UiO-66- $\mathrm{NH}_{2}$ with high $\mathrm{CO}_{2}$ adsorption capacity. Mater. Res. Bull. 2018, 98, 308-313. [CrossRef]

26. Cam Loc, L.; Thi Thuy Van, N.; Tri, N.; Tien Cuong, H. Synthesis, characterization and adsorption ability of UiO-66-NH 2 . Adv. Nat. Sci. Nanosci. Nanotec. 2015, 6, 2.

27. Cmarik, G.E.; Kim, M.; Cohen, S.M.; Walton, K.S. Tuning the adsorption properties of UiO-66 via ligand functionalization. Langmuir 2012, 28, 15606-15613. [CrossRef] [PubMed]

28. Zhang, X.-F.; Feng, Y.; Wang, Z.; Jia, M.; Yao, J. Fabrication of cellulose nanofibrils/UiO-66-NH 2 composite membrane for $\mathrm{CO}_{2} / \mathrm{N}_{2}$ separation. J. Membrane Sci. 2018, 568, 10-16. [CrossRef]

29. Nguyen, T.-B.; Rodrigue, D.; Kaliaguine, S. In-situ cross interface linking of PIM-1 polymer and UiO-66-NH for outstanding gas separation and physical aging control. J. Membrane Sci. 2018, 548, 429-438.

30. Valenzano, L.; Civalleri, B.; Chavan, S.; Bordiga, S.; Nilsen, M.H.; Jakobsen, S.; Lillerud, K.P.; Lamberti, C. Disclosing the complex structure of UiO-66 metal organic framework: A synergic combination of experiment and theory. Chem. Mater. 2011, 23, 1700-1718. [CrossRef]

31. DeStefano, M.R.; Islamoglu, T.; Hupp, J.T.; Farha, O.K. Room-temperature synthesis of UiO-66 and thermal modulation of densities of defect sites. Chem. Mater. 2017, 29, 1357-1361. [CrossRef]

32. Trickett, C.A.; Gagnon, K.J.; Lee, S.; Gandara, F.; Buergi, H.-B.; Yaghi, O.M. Definitive molecular level characterization of defects in UiO-66 crystals. Angew. Chem. Int. Ed. 2015, 54, 11162-11167. [CrossRef]

33. Katz, M.J.; Brown, Z.J.; Colon, Y.J.; Siu, P.W.; Scheidt, K.A.; Snurr, R.Q.; Hupp, J.T.; Farha, O.K. A facile synthesis of UiO-66, UiO-67 and their derivatives. Chem. Commun. 2013, 49, 9449-9451. [CrossRef]

34. Li, L.; Yang, J.; Li, J.; Chen, Y.; Li, J. Separation of $\mathrm{CO}_{2} / \mathrm{CH}_{4}$ and $\mathrm{CH}_{4} / \mathrm{N}_{2}$ mixtures by M/DOBDC: A detailed dynamic comparison with MIL-100(Cr) and activated carbon. Microporous Mesoporous Mater. 2014, 198, 236-246. [CrossRef]

35. Ling, Y.; Yang, F.; Deng, M.; Chen, Z.; Liu, X.; Weng, L.; Zhou, Y. Novel iso-reticular Zn(II) metal-organic frameworks constructed by trinuclear-triangular and paddle-wheel units: Synthesis, structure and gas adsorption. Dalton Trans. 2012, 41, 4007-4011. [CrossRef]

36. Millward, A.R.; Yaghi, O.M. Metal-organic frameworks with exceptionally high capacity for storage of carbon dioxide at room temperature. J. Am. Chem. Soc. 2005, 127, 17998-17999. [CrossRef]

37. Ethiraj, J.; Albanese, E.; Civalleri, B.; Vitillo, J.G.; Bonino, F.; Chavan, S.; Shearer, G.C.; Lillerud, K.P.; Bordiga, S. Carbon dioxide adsorption in amine-functionalized mixed-ligand metal-organic frameworks of UiO-66 topology. ChemSusChem 2014, 7, 3382-3388. [CrossRef] [PubMed]

38. Myers, A.L.; Prausnitz, J.M. Thermodynamics of mixed-gas adsorption. AICHE J. 1965, 11, $121-127$. [CrossRef]

39. Chen, Y.; Lv, D.; Wu, J.; Xiao, J.; Xi, H.; Xia, Q.; Li, Z. A new MOF-505@GO composite with high selectivity for $\mathrm{CO}_{2} / \mathrm{CH}_{4}$ and $\mathrm{CO}_{2} / \mathrm{N}-2$ separation. Chem. Eng. J. 2017, 308, 1065-1072. [CrossRef]

40. Lin, R.B.; Chen, D.; Lin, Y.Y.; Zhang, J.P.; Chen, X.M. A zeolite-like zinc triazolate framework with high gas adsorption and separation performance. Inorg. Chem. 2012, 51, 9950-9955. [CrossRef] 
41. Lefebvre, C.; Rubez, G.; Khartabil, H.; Boisson, J.-C.; Contreras-García, J.; Hénon, E. Accurately extracting the signature of intermolecular interactions present in the NCI plot of the reduced density gradient versus electron density. Phys. Chem. Chem. Phys. 2017, 19, 17928-17936. [CrossRef]

42. Yao, K.X.; Chen, Y.; Lu, Y.; Zhao, Y.; Ding, Y. Ultramicroporous carbon with extremely narrow pore distribution and very high nitrogen doping for efficient methane mixture gases upgrading. Carbon 2017, 122, 258-265. [CrossRef]

43. Lu, Y.; He, J.; Chen, Y.; Wang, H.; Zhao, Y.; Han, Y.; Ding, Y. Effective acetylene/ethylene separation at ambient conditions by a pigment-based covalent-triazine framework. Macromol. Rapid Commun. 2018, 39, 1700468. [CrossRef] [PubMed]

44. Adsorption Locator; Version 7.0; For A Module in the Materials Studio Modeling Software Package; Accelrys Inc.: San Diego, CA, USA.

45. Perdew, J.P.; Burke, K.; Ernzerhof, M. Generalized gradient approximation made simple. Phys. Rev. Lett. 1996, 77, 3865-3868. [CrossRef]

46. Delley, B. An all-electron numerical method for solving the local density functional for polyatomic molecules. J. Chem. Phys. 1990, 92, 508-517. [CrossRef]

47. Delley, B. From molecules to solids with the DMol3 approach. J. Chem. Phys. 2000, 113, 7756-7764. [CrossRef]

48. Lu, T.; Chen, F. Multiwfn: A multifunctional wavefunction analyzer. J. Comput. Chem. 2012, 33, 580-592. [CrossRef] [PubMed]

Sample Availability: Samples of the compounds are available from the authors.

(C) 2019 by the authors. Licensee MDPI, Basel, Switzerland. This article is an open access article distributed under the terms and conditions of the Creative Commons Attribution (CC BY) license (http://creativecommons.org/licenses/by/4.0/). 